\title{
Dussel y el suicidio
}

\author{
Julio CABRERA \\ Departamento de Filosofía \\ Universidad de Brasilia \\ kabra@unb.br
}

\begin{abstract}
Resumen: En su libro Ética de la liberación en la edad de la globalización y la exclusión (1998), Enrique Dussel presenta lo que él llama una "ética de la vida", poniéndola en el registro de su "ética de la liberación" y contraponiéndola a lo que denomina una dirección "suicida" del mundo actual. Sostengo que la "ética de la vida" de Dussel no puede defender simultáneamente el "principio material universal de ética" (el principio de la "producción, reproducción y desarrollo de la vida"), la condenación ética sin atenuantes del suicidio y la legitimación ética de la lucha por la liberación (que incluye, inevitablemente, una legitimación del heterocidio). Los resultados de mi trabajo sugieren que Dussel mantiene la plena legitimación ética del heterocidio, para lo cual debe aceptar debilitar el "principio material" y la condenación del suicidio.
\end{abstract}

Palabras clave: vida, suicidio, heterocidio, ética

\begin{abstract}
In his recent book, Ética de la liberación en la edad de la globalización y la exclusión (1998), Enrique Dussel presents his "ethics of liberation" as an "ethics of life" opposed to "suicide tendencies" in the modern world. This paper addresses certain difficulties in Dussel's statement of the material principle of respect of human life, the ideal of social liberation and the absolute refusal of suicide at the same time. I maintain that Dussel is constrained to some reformulation of at least one of these three issues. In fact, Dussel is compelled to keep the principle of liberation as the main support of his ethics, admitting crucial reformulation of the material principle of respect of human life and some sort of moral tolerance concerning suicide.
\end{abstract}

Key words: life, suicide, homicide, ethics

1. El proyecto dusseliano de una "ética de la vida" y la denuncia del "suicidio colectivo". La formulación del principio PV

En su libro Ética de la liberación en la edad de la globalización y la exclusión, Enrique Dussel comienza denunciando lo que denomina un comportamiento de "suicidio colectivo" imperante en el mundo actual, y le opone una "ética de la afirmación total de la vida". Al hablar de "suicidio colectivo" se refiere al proceso de sistematización global que excluye actualmente a la mayoría de la humanidad, y también a la cuestión ecológica como explotación irracional de la naturaleza.

Es un problema de vida o muerte. Vida humana que no es un concepto, una idea, ni un horizonte abstracto, sino el modo de realidad de cada ser humano concreto, condición absoluta de la ética y exigencia de toda liberación. No debe extrañar, entonces, que esta Ética sea una ética de afirmación rotunda de la vida humana ante el asesinato y el suicidio colectivo a los que la humanidad se encamina de no cambiar el rumbo de su accionar irracional. (p. 11) 
[L]a especie humana decidirá "corregir" ética o autorresponsablemente los efectos no-intencionales del capitalismo tecnológico desvastador, o la especie como totalidad continuará su camino hacia el suicidio colectivo. (p. 140)

Para enfrentar esta situación, es necesario considerar la vida como último punto de referencia o como principio supremo. Dussel sostiene que el ser humano cambia el mero impulso instintivo animal de conservación de la vida por un motivo cultural de preservación responsable de la misma. Así, un principio normativo que tiende hacia la vida surgiría de un estado de hecho, superando los niveles puramente biológicos.

El principio ético fundamental, que Dussel llama "principio material universal de la ética" y al cual se refiere desde el comienzo del capítulo 1 de su obra, recibe una formulación más acabada al final del mismo:

El que actúa éticamente debe (como obligación) producir, reproducir y desarrollar autorresponsablemente la vida concreta de cada sujeto humano, en una comunidad de vida, desde una 'vida buena' cultural e histórica [. . .] que se comparte pulsional y solidariamente, teniendo como referencia última a toda la humanidad. (p. 140)

A esto Dussel lo llama "un enunciado normativo con pretensión de verdad práctica y, además, con pretensión de universalidad" (ibid.). Voy a denominar "principio de la vida" (o PV) a este principio material.

En la segunda parte de la obra, Dussel trata las cuestiones críticonegativas del proceso de aplicación del PV. Comienza situándose en la perspectiva de las víctimas, o sea, de los excluidos por el sistema global, que puede considerarse "malo" en la estricta medida en que no deja que la vida de sus víctimas se produzca, se reproduzca y se desarrolle. "La 'verdad' del sistema es ahora negada desde la 'imposibilidad de vivir' de las víctimas" (p. 310). El sufrimiento, la pobreza y la exclusión dan origen a la "conciencia crítica" y al reconocimiento ético de "la dignidad de la víctima" (p. 372). Dussel reconoce:

El más difícil de los principios éticos [...] es el principio material universal [...]. De la afirmación de la vida se puede fundamentar la no aceptación de la imposibilidad de reproducir la vida de la víctima, en donde se toca el hontanar desde donde se puede (y se debe) ejercer la crítica contra el sistema que es responsable de dicha negatividad. (pp. 368-369)

Mi propósito último en este trabajo es evaluar, ante este panorama, las cuestiones del suicidio y el heterocidio ${ }^{1}$ en la ética de Enrique Dussel. En

\footnotetext{
${ }^{1}$ Así denomino a la eliminación de otra persona diferente de la mía. No hablo de "homicidio" (que significa dar la muerte a un ser humano) porque, en sentido estricto, este término incluiría también el suicidio.
} 
relación con estas cuestiones, dos problemas iniciales surgen inmediatamente de la mera lectura del PV: (1) ¿de qué "vida" se trata?, y (2) ¿de la vida "de quién"? La pregunta (1) puede responderse diciendo que se trata o bien de la "vida" como puro permanecer en el mundo de manera preservadora (la vida-permanencia), o bien de la "vida" con algún tipo de calificación (una vida digna, una vida humana, una vida superior, etc.: la vida-calificada). La pregunta (2) se puede responder diciendo que se trata de la vida de todos o de la vida de no-todos ("vida" se puede entender aquí en alguno de los dos sentidos apuntados). Así, tenemos las siguientes posibilidades de interpretación del PV:

(1) Es obligatorio producir, reproducir y desarrollar la vida-permanencia de todos.

(2) Es obligatorio producir, reproducir y desarrollar la vida-calificada de todos.

(3) Es obligatorio producir, reproducir y desarrollar la vida-permanencia no de todos.

(4) Es obligatorio producir, reproducir y desarrollar la vida-calificada no de todos.

Esto sugiere que tal vez el PV, en alguna de sus formulaciones, como en (4), pudiera ser compatible con la muerte física (biológica) de ciertas personas, si esto salvaguarda, de algún modo, la vida "auténticamente humana". Dicho de otra manera, el PV podría ser compatible con alguna forma "legítima" de heterocidio. Pero esto parece contradecir la intención del PV de referirse a la vida de todos (como en las versiones (1) y (2)). La versión (3) es la menos admisible, porque pretendería enunciar tan sólo una obligación de mantener la vida-permanencia de algunos, pero no la de todos; parece más plausible la exclusión de alguien cuando se trata de una obligación hacia la vida-calificada de algún modo. Si, para evitar estos problemas, volvemos a la idea de "vida" sin calificaciones, como pura permanencia en la vida y reproducción de la misma, parece extraño que la "producción, reproducción y el desarrollo" de la propia vida se considere como una obligación moral. Tenemos la fuerte percepción de que la moralidad y la preservación de la propia vida podrían entrar en conflicto y que, para salvar a la moralidad, tal vez fuera preciso arriesgar la preservación de la propia vida; por el contrario, la indefinida preservación de la propia vida podría llevar, tal vez, a la inmoralidad. Asimismo, si entendemos "reproducción" en el sentido literal como "engendrar seres humanos", parece igualmente extraño poner eso como una exigencia moral, en virtud de lo cual deberíamos considerar inmorales a los abstinentes. 
Lo que trataré de mostrar en lo que sigue es que Dussel cambia la noción de "vida" y la propia interpretación del PV según se refiera a la propia vida o a la vida del otro, lo que produce evaluaciones asimétricas (y, creo yo, injustificadas) del suicidio y del heterocidio. En efecto, cuando se trata de la propia vida, parece acentuarse la vida-permanencia, de tal forma que permanecer en la vida se torna un deber moral para cada uno de nosotros (así como hacer algo para reproducir la vida-permanencia). Pero cuando se trata de la vida del otro, parece acentuarse fuertemente algún tipo de vidacalificada. Así, la vida parece no tener ninguna calificación cuando se impone como deber para uno mismo, pero parece ganar calificaciones cuando nos damos el derecho de eliminar al otro. Pero, ¿por qué la eliminación de la propia vida no podría realizarse en nombre de una vida calificada, y por qué el respeto a la vida ajena no podría basarse en la vida como mera permanencia? Voy a tratar de mostrar que Dussel entiende el PV tal como se plantea en la versión (4): contra las primeras apariencias, no se trata de cualquier vida, y no se trata de la vida de todos; se trata, pues, de una "ética de la vida" con fuertes restricciones. Al tenerlas, se puede preguntar si esa ética es eficaz para enfrentar la situación mundial de "asesinato" y "suicidio colectivo" denunciada por Dussel, o si de algún modo contribuye a que esa situación continúe.

\section{Paradojas en la condenación del heterocidio}

Al hablar del principio formal de la moralidad, en el capítulo 2 de su libro, Dussel acentúa la relación estrecha con el principio material, oponiéndose a las éticas formalistas:

[D]el enunciado: [...] Los seres humanos somos vivientes, se puede fundamentar, como ejercicio de la razón práctico-material, y no como una deducción lógico-formal analítica: [...] Debemos vivir. No debemos dejarnos morir, ni debemos matar a nadie [...]; porque la vida es la condición absoluta y el contenido constituyente de la realidad humana [...], se nos impone como un imperativo de cuidarla, de conservarla. (pp. 208-209)

Nótese que, dado el carácter totalmente genérico y universal del PV, Dussel siempre coloca, dentro del mismo imperativo, el no matarse y el no matar, sin ninguna desconfianza inicial acerca de la posible incompatibilidad entre ambas cosas. En la ya mencionada denuncia dusseliana de la exclusión y en sus pensamientos sobre el clamor de la víctima ("sumida en el 'dolor', 'infelicidad', 'pobreza', 'hambre', 'analfabetismo', 'dominación'”, p. 310) reside lo mejor de sus críticas contra el heterocidio, afirmaciones con las que sólo se puede estar de acuerdo: "si las instituciones son la repetición de actos exitosos para evitar el dolor y postergar la muerte y así alcanzar la 
felicidad, la 'víctima' es su contradicción absoluta —ya que siendo fruto de esta institución, sufre sin embargo dolor y anticipa su muerte" (p. 370).

Hay, pues, en el mundo una situación de heterocidio sistemático ya instalada. ¿Qué hacer? Específicamente, ¿en qué condiciones se encuentra el PV para enfrentar esa situación? El problema inicial es que el PV se refiere a la "producción, reproducción y el desarrollo de la vida concreta de cada sujeto humano", sin hacer distinciones, en principio, entre la vida de la víctima y la del verdugo. De esta manera, el PV debería considerar tembién la producción, la reproducción y el desarrollo de las vidas de Calígula, Nerón, Enrique VIII, Stalin, Hitler, McCarthy, Pinochet, Stroessner, Videla, Saddam Hussein, Bin Laden y de todos los presidentes estadounidenses y de países ricos en general que practican políticas exclusionistas y productoras de miseria. Debería preocuparse por salvaguardar los proyectos de vida de esas personas, puesto que es antiético hacer cualquier cosa para impedir su realización. A esto, el defensor del PV puede replicar dirigiendo nuestra atención hacia el resto de la formulación del principio: se trata de producir, reproducir y desarrollar la vida, pero a partir de una "vida buena". Parecería evidente que las personas mencionadas en esa lista no estaban interesadas en esa "vida buena"; sin embargo, el problema es que, a partir de esta calificación de la vida, el PV debería permitir que se impidiera la producción, la reproducción y el desarrollo de vidas que impiden la producción, la reproducción y el desarrollo de vidas guiadas por la "vida buena". Esto debe, pues, imponer alguna restricción en el PV, que trata de la vida de cada sujeto humano sin restricciones. En verdad, el PV se refiere tan sólo a la vida "de cada sujeto humano guiada por la "vida buena" ", o sea, a un tipo de vida calificada. Parece que no se puede hacer compatible la referencia a la totalidad de los seres humanos con la necesidad de combatir a los que impiden el establecimiento de la moralidad. Pero aún a esto el defensor del PV podría replicar llamando la atención hacia la última parte de la formulación del principio: "teniendo como referencia última a toda la humanidad". Quiere decir que, implícitamente, el PV estaría asumiendo que aún no ha llegado la hora de la moralidad completa, que la universalidad del principio puede y debe suspenderse para combatir por ahora a todos los que impiden la moralidad de la "vida buena", hasta que llegue el momento en que el PV pueda aplicarse a toda la humanidad y pueda defenderse la vida sin calificaciones.

El PV debería leerse, entonces, en una secuencia temporal. En una paráfrasis plausible, significaría algo así como: "Aquel que actúa éticamente debe (como obligación) producir, reproducir y desarrollar autorresponsablemente la vida concreta de cada sujeto humano que esté dispuesto a guiar su vida, en una comunidad de vida, a partir de una 'vida buena' cultural e histórica, resistiendo y combatiendo a los que se oponen a esta 'vida buena', resistencia y combate que deben continuar hasta que todos 
puedan ser guiados por la 'vida buena'." Sin una paráfrasis de este tipo, o sin agregar algunas nuevas distinciones, la formulación del PV corre serios riesgos de caer en una paradoja.

El problema con el PV es qué principio moral se ha de utilizar con aquellos que lo violan o que no están dispuestos a seguirlo: si el propio PV, u otro principio diferente, o el mismo principio parafraseado (de la manera sugerida o de otra). Se crea aquí la siguiente paradoja: para defender el PV, que es un principio de vida, se debe estar dispuesto a resistir, y, si fuera necesario, a eliminar a todos aquellos que se oponen al principio de vida. Los que se oponen a la defensa irrestricta de la vida deben morir. Es en este sentido que afirmo - en la medida en que el PV debería guiar materialmente a una "ética de la liberación" - que la condenación inicial del heterocidio, dentro de esta ética, es paradójica. (Veremos que el problema con el suicidio es otro, diferente de la paradoja.)

Toda la tematización dusseliana de la cuestión de la violencia, en el capítulo 6 de su libro, está conducida siempre al borde de esta misma paradoja, pues parecería que una "ética de la liberación" debería legitimar algún tipo de violencia. Dussel trata de protegerse de esta posibilidad ya desde el comienzo de su reflexión: "Una teoría sobre estas cuestiones no es necesariamente una justificación de la violencia, aunque frecuentemente lo haya sido, sino, muy por el contrario, debe encaminarse a mostrar cómo la coacción se transforma en violencia cuando pierde legitimidad" (p. 539). La noción de "coacción legítima" se torna aquí fundamental, ya que es ella la que debe permitir el tratamiento desconsiderado (ihasta las últimas consecuencias!) de aquellos que se niegan a integrarse al proyecto guiado por el PV. El término "violencia" lo reserva Dussel para la desconsideración y el heterocidio ejercidos cuando no se tiene como objetivo final el PV o cuando se ejerce con crueldad (por ejemplo, mediante la tortura). Al lado de ellos, hay "usos de la fuerza que son legítimos, legales, justos, honestos y hasta meritorios, dada la heroicidad de aquel que la ejerce por deber y como servicio ético para la comunidad, para la humanidad". Las víctimas del sistema, al reconocer su propia negatividad, reaccionan contra las coacciones falsamente legitimadas por el sistema, que se basa en normas en cuya formulación ellas (las víctimas) no participaron, y que no permite que sus vidas se desarrollen. Es "violenta", en el sentido técnico de Dussel, la acción represora del sistema contra la acción reivindicadora legítima de los excluidos, que no es "violenta":

La lucha por el re-conocimiento de los nuevos derechos [...], cuando son el último recurso posible de las comunidades críticas de las víctimas, consiste, en su límite, y aun cuando se usen medios "proporcionados" a la violencia contraria [...], en la praxis de la liberación legítima, coacción defensiva de la masa inocente de víctimas, sin estructuras legales que justifiquen todavía sus acciones, evidentemente. (p. 549) 
(En el mismo lugar, Dussel llega a introducir diferencias éticas entre ejércitos.) Al introducir lo que llama el "principio de liberación", dice que "Este principio subsume a todos los anteriores principios" (p. 559) y otorga a las personas el derecho a defenderse, a reivindicar sus derechos ofendidos y a reaccionar contra sus opresores, incluso con sus mismos instrumentos (propaganda, armas, etc.). En todo momento, Dussel considera esto como una "ética" y, en la conclusión del capítulo (y del libro), proclama: "La ética deviene así el último recurso de una humanidad en peligro de autoextinción" contra el peligro de "suicidio colectivo" (p. 568).

Pero admitir una asimetría entre la muerte que $X$ daría a $Y$ y la muerte que $Y$ daría a $X$, en el sentido de justificar sólo a una de las partes, responde a una profunda falta de reconocimiento de la negatividad interna de todo proyecto humano. Lo mismo vale para el "estado de derecho" que pretende que dar muerte a "subversivos" está justificado de una manera en que no lo está que éstos den muerte a otras personas. A la luz de la idea de una inviolabilidad negativa entre los seres humanos (la intuición de que todos estamos en la misma condición, a partir de un desamparo fundamental y compartido), la simetría moral en la evaluación de situaciones de heterocidio debería ser total. Si hay asimetría, significa que la negatividad básica - lo que suelo llama la "mortalidad del ser"-, vinculada con la finitud de los proyectos humanos, no está siendo considerada. ${ }^{2}$ La mortalidad del ser se refiere a la situación que nos rebasa por completo, a la que hemos sido arrojados desde el nacimiento, del carácter terminal de todos nuestros proyectos de creación y de desarrollo de nuestra vida; es decir, se refiere al hecho insuperable de que, a partir de nuestro nacimiento, todos nuestros proyectos de "producción, reproducción y desarrollo" (para usar los términos específicos de Dussel) se encuentran en cuenta regresiva hacia la consumación de una terminalidad iniciada desde siempre. La importancia que la mortalidad del ser tiene para cualquier proyecto práctico-político es evidente: el hombre al que queremos liberar, y nosotros mismos, en cuanto críticos libertadores, estamos desde siempre afectados, en la misma raíz de nuestros proyectos, por la mortalidad del ser. Al pensamiento de Dussel no le falta sensibilidad para el pensamiento negativo, pero no considera con atención esta negatividad.

Está claro que vemos las diferencias entre el PV y el programa nacionalsocialista, y parece más justificable legitimar acciones heterocidas en el primer caso que en el segundo. Pero, en ambos casos, la actitud de eliminar, en nombre de un programa basado en una determinada percepción del bien, a los que se oponen a él es formalmente la misma, con el agravante de que eliminar personas en nombre del PV cae en paradojas en las que el programa nacional-socialista no cae, ya que éste, desde el inicio, tiene por objeto

\footnotetext{
${ }^{2}$ He desarrollado este tema en la Crítica de la moral afirmativa (1996) y en "Ética negativa, ética de la liberación" (inédito).
} 
la depuración y el exterminio, mientras que un programa basado en el PV, como el de Dussel, es, desde el comienzo, de defensa de la "producción, la reproducción y el desarrollo de la vida". Parece, pues, que el programa del PV se verá obligado a mantener siempre en acción a su policía y su programa heterocida de "defensa" del principio PV. Y esto, formalmente, no tiene fin. Si existe en la actualidad una situación de "suicidio colectivo", todas las partes beligerantes forman parte de él, y no sólo algunas de ellas. No veo cómo la ética de Dussel pueda escapar al peligro de estar participando en ese mismo proceso, desde el momento en que acepta la "coacción legítima" como el permiso para eliminar a los "violentos" excluidores de la mayoría de la humanidad. La "ética de la liberación" es un claro llamado a la lucha. Si no hay ningún tipo de cesión, de sacrificio o de movimiento contrario a esa terrible dinámica, también la "ética de la liberación" estará contribuyendo al proceso de "suicidio colectivo".

Desde mi perspectiva, la ética de la liberación de Dussel es típicamente una ética "de segundo grado", 3 en la que ya hace tiempo la vida humana ha dejado de ser inviolable en sí misma (a pesar del PV), en la medida en que se la ha dividido, de algún modo, en "vida que debe respetarse" y "vida que puede suprimirse". Las maneras de evitar la paradoja no son muchas: o se asume una ética de primer grado, en la que la vida del Otro sea inviolable sin calificaciones, de tal forma que los heterocidios salgan simplemente fuera de la moralidad (y ésta es la tendencia de mi ética negativa), o se acepta algún tipo de politización de la ética, que será de segundo grado, y para la cual la vida humana es ético-políticamente calificada. Pero no se puede politizar la ética y admitir, al mismo tiempo, la inviolabilidad de la vida (calificada) de todos, pues politizar la ética nos llevará a matar, y abstenernos de matar nos impedirá politizar la ética.

El camino auténticamente ético me parece otro. En primer lugar, se debería dejar de hablar indistintamente de "la vida", y entonces diferenciar desde el inicio la propia vida y la vida del otro. Parece que no se pueden defender al mismo tiempo y bajo el mismo principio, sin caer en paradojas, la propia vida y la vida del otro. En segundo lugar, el PV tendría que ser reformulado, transformándolo explícitamente (con bases levinasianas, caras a Dussel) en un principio de preservación de la vida del otro en cada caso (tu vida es la vida del otro para mí, mi vida es la vida del otro para ti), y no de la propia vida. El principio debería poner mi propia vida en riesgo (no la mía en particular, la vida de Julio Cabrera, sino mi vida "en cada caso mía"). En tercer lugar, el PV tiene que enunciarse irrestrictamente, o sea, valer $a b$ initio (y no tan sólo como un "horizonte") para todos los sujetos humanos sin ninguna calificación, en la estricta medida en que ellos sean el otro para alguien. Las consecuencias de todo esto tienen que ser exami-

${ }^{3}$ Cfr. Cabrera 1996, pp. 135-136. 
nadas. Mi idea es que no es posible introducir estas modificaciones sin que se acepte el sacrificio de la propia vida en el conflicto y, consecuentemente, una moralidad del suicidio, que Dussel explícitamente niega. Vamos, pues, al suicidio.

\section{Inconsecuencias en la condenación del suicidio}

En varios momentos de su exposición, Dussel hace un contrapunto entre la exigencia del PV y la actitud del "suicida":

Toda norma, acción, micro-estructura, institución o eticidad cultural tiene siempre y necesariamente como contenido último algún momento de producción, reproducción y desarrollo de la vida humana en concreto. El acto límite, que pudiera parecer que no tiene ya por contenido a la misma vida, el suicidio, de ninguna manera es una excepción. El suicida, en primer lugar, no podrá fundamentar éticamente su auto-negación absoluta; no podrá tampoco sobre el suicidio fundar una acción ética posterior o un orden social, ya que se niega como sujeto de toda acción posterior. Pero aún más, si cansado, desmotivado o sufriente se "quitara la vida", la supone siempre, ya que es exactamente por haber perdido sentido su vida concreta por lo que intenta extinguirla: la vida no vivible funda la posibilidad de negar la vida: el suicidio. (pp. 91-92)

Creo que Dussel no escapa, en este texto, a la acostumbrada superficialidad con la que los filósofos han abordado la cuestión del suicidio a lo largo de toda la historia del pensamiento. El suicidio no es necesariamente ni contradictorio ni antiético, aunque pueda haber suicidios que lo sean. Como cualquier otro acto humano, el suicidio puede ser coherente o no serlo, puede ser ético o no. Hablando en general, el precepto absoluto de "conservar la propia vida", si se lo defiende como pretenso precepto moral (véanse, por ejemplo, las pp. 138 y ss.), es insostenible. Es completamente intuitivo (y Dussel mismo lo acepta) que preservar la propia vida puede ser antiético, moralmente indigno (como cuando le ofrecieron a Sócrates posibilidades de fuga para evitar su condena de muerte, que él no aceptó; en cierto sentido, podemos decir que se suicidó o que por lo menos no hizo ningún esfuerzo por "preservar" su vida). A veces, el ejercicio de la moralidad supone que yo no deba continuar viviendo; puedo, entonces, suicidarme (o dejar que me maten, que da lo mismo), y mi acto de autosupresión tendrá un evidente sentido moral.

Por el contrario, para intentar probar que tendríamos algo como una obligación moral de conservar la propia vida, Dussel desarrolla (p. 139) el siguiente razonamiento:

1. Juan, que es un sujeto humano viviente, responsable de sí mismo, está comiendo. 
2. Para vivir, es necesario comer.

3. Si Juan dejase de comer, moriría, se suicidaría.

4. Como responsable de su vida no debe dejarse morir, o sería un suicida. Ergo,

5. Juan debe continuar comiendo.

Dussel pretende haber desarrollado un mecanismo inferencial que evita la famosa "falacia naturalista" del paso de un hecho (querer preservar la vida) a un deber (se debe preservar la vida). Sostiene que no se trata, ciertamente, de un paso deductivo formal abstracto, sino de una fundamentación dialéctico-material, de ejercicio de razón práctico-material, pues los juicios sobre la vida humana serían "especiales" desde un punto de vista material, ya que las necesidades humanas básicas (alimentarse, vestirse, etc.) no son únicamente descripciones de hechos, sino también exigencias, deberes, obligaciones. Sin embargo, el paso inferencial de (1)-(3) a (4)(5) es falaz no sólo desde el punto de vista formal, sino también desde el punto de vista material. En mis estudios sobre lógica y argumentación me he ocupado activamente de lo que denomino "inferencias lexicales", o sea, las conexiones entre piezas lexicales habitualmente consideradas como "materiales" y "extralógicas" por los lógicos formales y como indignas, por consiguiente, de todo tratamiento formal. ${ }^{4}$ Pero ni siquiera lexicalmente podría considerarse legítimo el paso mencionado: si $x$ está vivo, y va a morir si no come, él tiene la responsabilidad de decidir si continúa vivo o no, y no la responsabilidad de continuar vivo. Esto no tiene nada que ver con la "falacia naturalista", sino con simples conexiones materiales (de las que la lógica formal no se ocupa). Por qué los enunciados sobre la vida humana tendrían algún privilegio que los eximiría de obedecer a las simples exigencias materiales de conexión lexical es algo que aún debería explicarse. Podría alegarse que "la vida es la condición absoluta y el contenido constituyente de la realidad humana; y como dicha vida está 'bajo nuestra responsabilidad' comunitaria [...] se nos impone como un imperativo de cuidarla, de conservarla" (p. 209). Pero la exigencia de conservación de la vida no se desprende (ni formal ni materialmente) de la premisa de que estamos vivos. Lo que se desprende de esa premisa es, precisamente, la responsabilidad de decidir si vamos o no a conservar la vida (y es posible que ciertos criterios morales influyan en esta decisión) y no una presunta responsabilidad de conservarla. La moralidad no está hipotecada por la

\footnotetext{
${ }^{4}$ Cfr. Cabrera 1987 e "Inferencias lexicales e interpretación-red de predicados" (en colaboración con Olavo Da Silva, inédito).
} 
conservación de la vida, ya que puede ser moral no conservarla (e inmoral retenerla). ${ }^{5}$

Por otro lado, Dussel mantiene siempre la exigencia de "preservar la vida" abarcando tanto la propia vida como la vida del otro, ignorando, de cierta forma, el carácter dramático de las decisiones humanas, que podría tornar imposible cumplir ambas cosas simultáneamente. No obstante, la exigencia moral fundamental parece referirse a la preservación de la vida del otro, y no de la mía. Si se piensa bien, los comportamientos suicidas, en la medida en que perjudican primeramente al propio agente, y no al otro, están más cerca del principio moral de considerar los intereses ajenos que los comportamientos heterocidas, permitidos como éticos por Dussel. El heterocidio está mucho más cerca de la incoherencia, la paradoja y la "autocontradicción performativa" que el suicidio: matar en nombre de la vida, en todo caso, no es menos contradictorio que matarse en nombre de la vida. No parece tan contradictorio incluir el suicidio, como aceptación de la propia eliminación, dentro del "producir, reproducir y desarrollar la vida", como sí parece abiertamente contradictorio incluir el heterocidio dentro del mismo, como lo hacen abiertamente las "éticas de la liberación".

En la Crítica de la moral afirmativa he presentado una serie de justificaciones éticas del suicidio basándome en esta línea de razonamiento: mediante el suicidio se evita, en casos de conflicto, la inhabilitación moral heterocida (piénsese, por ejemplo, en el suicidio de Walter Benjamin), y se consigue, por así decirlo, la indefinida postergación de la muerte del otro a través de la propia muerte, o sea, el hecho de que, con mi suicidio, la vida del otro queda indefinidamente salvaguardada, en lo que a mí se refiere. En segundo lugar, he tratado de enfatizar la enorme potencia subversiva del suicidio, o sea, el tremendo poder de rebeldía que deja tras de sí el acto suicida, y que puede tener consecuencias de larga duración. ${ }^{6}$ Creo que Dussel se equivoca cuando afirma que el suicida "se niega como sujeto de toda acción posterior". La fuerza subversiva de la propia eliminación puede atravesar siglos, en la medida en que no precisamos estar físicamente presentes para ser sujetos de acciones posteriores a nuestra desaparición.

\footnotetext{
${ }^{5}$ Ya en su artículo "Algunas reflexiones sobre la 'falacia naturalista'", Dussel salta (ilegítimamente, a mi entender) de una noción de "responsabilidad" a otra diferente durante su argumentación: en la premisa 2 (p. 72) usa "responsabilidad sobre su vida" de una manera neutra (responsabilidad de conservar o no la vida), mientras que en la conclusión, usa "responsable" ya como responsabilidad de conservar la vida. Cfr: "porque el 'ser humano' como tal es ya un 'sujeto ético', es 'responsable' de su vida, y queda 'obligado' también (ésta es la normatividad 'oculta' del juicio empírico) al querer vivir, o al menos a seguir viviendo" (pp. 73-74). Concede que alguien puede decidir no continuar viviendo, pero con eso "se contradice". La cuestión es totalmente definicional: si se define "responsabilidad" como responsabilidad de conservar la vida, seremos irresponsables si no la conservamos.

${ }^{6}$ Cfr. Cabrera 1996, pp. 71-85. Véanse otros argumentos disponibles en favor de una moralidad del suicidio en Kamlah 1976.
} 
Como ya está implícito en las reflexiones anteriores, creo que para hacer una ponderación profunda de las relaciones entre moralidad y suicidio es conveniente diferenciar entre los suicidios "directos" (como el de Ernest Hemingway, Virginia Woolf o Benjamin) y los que llamo suicidios "indirectos". No es descabellado considerar las muertes de Martin Luther King, Mahatma Gandhi, Leon Trotski, Sócrates o Cristo como cierto tipo de muertes voluntarias, vecinas al suicidio directo, puesto que se trata de personas que, como se dice popularmente, "se metieron en la boca del lobo", asumieron tareas que ellos sabían que eran extremadamente peligrosas, y murieron en ellas. En varios textos, Dussel admite abiertamente la moralidad de ciertas muertes voluntarias, vecinas del suicidio, como riesgo de la propia vida en situaciones altamente peligrosas (pp. 132, 379, 412, etc.). También: "Quien da su vida en esta lucha por el reconocimiento de la dignidad de las víctimas inocentes, en su defensa, será recordado justamente por las generaciones futuras, por la historia, como héroes" (p. 541; véase también la p. 560). Una huelga de hambre dentro de una fábrica tomada por obreros, en protesta por los abusos de la explotación, en el caso de que haya muertos por inanición, debe ser justificada éticamente dentro de una ética de la liberación. Si se acepta esto, debe entenderse que morir por inanición en esas circunstancias responde al principio de "producción, reproducción y desarrollo de la vida", con lo cual la muerte es colocada dentro de una dialéctica compleja con la vida, y no en términos de su mera interrupción. Más allá de toda morbidez o "necrofilia" (pp. 94, 381), la muerte puede ser subversiva, tener sustancia y contenido trágico-revolucionario.

Ciertamente, Dussel puede replicar que el héroe libertador no es, en ningún sentido plausible, un "suicida" (ni siquiera "indirecto"), puesto que él muere "sin intención de morir", muere "por la vida". Pero a veces es difícil diferenciar entre suicidios directos e indirectos, como en el caso de Wittgenstein, que fue a la guerra para que le dieran un tiro (qué difícil habría sido clasificar su muerte si hubiera sido baleado). O pensemos en el caso de los ascetas que ayunan, buscando la perfección y la mortificación de la voluntad, y mueren por inanición: ¿se suicidaron, o murieron "naturalmente"? La "intención de morir" es difícil de identificar en esos casos. ¿Quién dice que el que se mete en una lucha libertadora (como el Che Guevara) no ha optado también por un tipo particular de muerte voluntaria? (El fuerte deseo del militar de "morir con las botas puestas".) Ciertamente se puede decir que el suicida directo muere matándose, mientras que el héroe libertador muere matando, pero los límites continúan difusos.

Así, pues, la condenación absoluta del suicidio, desde el punto de vista moral, y específicamente desde el punto de vista de la ética de la liberación, no parece sostenible. Dussel presenta la típica asimetría afirmativa entre la actitud completamente condenatoria del suicidio (del homicidio suicida) y la actitud mucho más flexible y elástica en lo que se refiere 
al heterocidio (al homicidio heterocida). Esta asimetría es típica de las morales afirmativas vigentes, para las que el acto de matarse merece ser condenado sin atenuantes, mientras que matar a los otros recibe muchas justificaciones (matar "en defensa propia", combatir la delincuencia, hacer la guerra, "ajusticiar" por la pena de muerte, etc.). En realidad, parece difícil ir simultáneamente contra las dos formas de homicidio, la suicida y la heterocida: si somos inflexibles en condenar el heterocidio, tendremos que admitir alguna forma (aunque sea indirecta) de suicidio, y si nos situamos frontalmente contra el suicidio en cualquier forma (como Dussel parece situarse), entonces deberemos, en nuestra ética, abrir un ámbito para poder matar moralmente a otras personas (que es, creo yo, el caso de las "éticas de la liberación"). Mantener la condenación de ambos al mismo tiempo, del suicidio y del heterocidio, supone situaciones no extremas, en las que la oposición y el conflicto aún pueden negociarse, o sea, contextos que interesan menos a una ética de la liberación.

A la luz de la preocupación estrictamente moral, el problema es determinar si es posible, sin caer en inconsistencias o paradojas, una "ética de la afirmación total de la vida humana" que sea, al mismo tiempo, una "ética de la liberación". Esto supone que la liberación no implica ninguna ofensa a la afirmación total de la vida humana, o, por el contrario, que la obediencia plena de esta afirmación total de la vida humana no perjudica el proyecto liberador. Parece que si el PV se entiende como principio universal para toda la humanidad, impedirá cualquier lucha por la liberación, y que si la lucha, incluso destructiva, por la liberación recibe legitimación, el PV no podrá sostenerse universalmente. Si el principio material realmente rige, entonces no puede haber, stricto sensu, una "ética de la liberación": la liberación puede tener que suspender la ética (como respeto por la vida del Otro), y la ética puede tener que suspender la liberación. Incluso optar ciega y fanáticamente por la moralidad, en el sentido de la obediencia absoluta al PV, con el consiguiente desarrollo de actitudes suicidas, sacrificantes y desocupantes, puede dejar todo el espacio a disposición de un grupo minoritario de poderosos que establezcan en el mundo su total hegemonía, con el sacrificio (que puede llegar a ser literal) de la mayoría de la humanidad.

Desde mi punto de vista ético-negativo, yo sería partidario de conservar un sentido restringido para el concepto de moralidad y aceptar que la moralidad puede ser incompatible con la preservación de la propia vida, y que, desde el punto de vista moral (siempre en este sentido restringido), debería universalizarse el PV y simplemente condenar moralmente todo tipo de heterocidio. De esto no me parece que se desprenda que no debamos tomar parte en luchas por la liberación cuando tengamos motivos poderosos para ello, y que incluso podamos llegar al extremo de comprometernos en una lucha armada, con la condición de que en ningún momento exijamos 
una justificación moral para lo que hacemos. Me parece mejor conceder que toda la cuestión de la opresión, la exclusión y la liberación tienen pleno sentido, pero que no pueden tratarse sólo mediante categorías morales.

Existe actualmente, en mi opinión, la tendencia a extender la moralidad como si toda la significación de los comportamientos humanos tolerase ser analizada moralmente. Esto me parece una inflación indebida de la esfera moral. Tenemos otros tipos de categorías racionales — políticas, pragmáticas, afectivas, etc.- para tratar de entender y evaluar comportamientos humanos, al lado de las categorías estrictamente morales. La moralidad no tiene el monopolio de la racionalidad categorial. No creo conveniente tratar de extender el ámbito de la moralidad para abarcar también todo el ámbito de lo racional, lo político, lo pragmático, etc. Parece más natural y trágico admitir que una gran parte de lo que los hombres nos vemos obligados a hacer cae fuera del ámbito de la moralidad, y ofende la obligación de no matar (como Lévinas dice, no se puede estar ahí sin poner ya en riesgo la vida del otro), en lugar de tratar de formular una moral política, una moral pragmática, etc. Creo que siempre que matamos salimos fuera del ámbito de la moralidad; pero también creo que podemos tener poderosos motivos racionales, pragmáticos y políticos para salir de la moralidad, y que eso establece una diferencia en relación con los casos en que no podemos ofrecer tales razones.

Es mejor admitir que, a pesar de optimismos neoliberales, continuamos en tiempos sombríos, nada propicios todavía para la instauración de un mundo guiado moralmente. Las "éticas de la liberación" son nombres inconsistentes para procedimientos bien adecuados para tiempos difíciles.

\section{BIBLIOGRAFÍA}

Cabrera, Julio, 1996, Crítica de la moral afirmativa, Gedisa, Barcelona.

—_, 1987, A Lógica Condenada, Hucitec/Edusp, São Paulo.

Dussel, Enrique, 2000 (1998), Ética de la liberación en la edad de la globalización y la exclusión, 3a. ed., Trotta, Madrid.

—_, 2001, "Algunas reflexiones sobre la 'falacia naturalista' (¿Pueden tener contenidos normativos implícitos cierto tipo de juicios empíricos?)", Diánoia, año XLVI, no. 46, pp. 65-79.

Kamlah, Wilhelm, 1976, Antropología filosófica y ética, Alfa, Buenos Aires.

Recibido el 7 de enero de 2003; revisado el 27 de junio de 2003; aceptado el 12 de agosto de 2003. 